\title{
Skin Adnexal Tumors: A Histopathological Study of 60 Cases at a Tertiary Care Centre
}

\author{
Alaka Sahu' ${ }^{1}$, Dilip Kumar Sa ${ }^{2 *}$, Salil Kumar Nayak ${ }^{1}$ and Kailash Chandra Agrawal ${ }^{1}$ \\ ${ }^{1}$ Department of Pathology, Veer Surendra Sai Institute of Medical Sciences and Research, Burla(India) \\ ${ }^{2}$ Department of Dermatology, Late Shri Lakhiram Agrawal Memorial Govt. Medical College, Raigarh India)
}

\begin{abstract}
Background: Skin adnexal tumors(SATs) are one of the most challenging areas of dermatopathology.SAT encompasses a large and a diverse group of benign and malignant neoplasms which exhibit morphological differentiation towards one of the different types of adnexal epithelium present in normal skin. The aim of this study is to study the spectrum and microscopic features of skin adnexal tumors.

Methods: A cross-sectional, descriptive study was conducted over a period of 5 years in the Department of Pathology,VIMSAR,Burla. Formalin fixed, paraffin embedded tissue sections were stained with hematoxylin and eosin stain for histopathological analysis.

Result: Out of total 60 cases diagnosed as adnexal neoplasm27(45\%) tumors were with sweat gland differentiation followed by tumors with sebaceous differentiation $19(31.66 \%)$ and follicular differentiation $14(23.33 \%)$. The age ranged from 11 years to 75 years and male to female ratio was $1.7: 1$.Mostof the tumors(78.33\%) were benign while only $21.66 \%$ were malignant. Eccrine poroma was the most common benign tumor while sebaceous carcinoma was the most common malignant tumor.
\end{abstract}

Conclusion: Architectural features are of great importance in differentiating benign tumors from malignant tumors in histopathology.

Keywords: Adnexal, Differentiation, Histopathology, Skin

\section{Introduction}

Skin adnexal tumors (SATs) are the tumors arising from the appendages of the skin such as sweat glands, sebaceous glands and hair follicles. They are often difficult to diagnose clinically and histopathology usually provides diagnostic confirmation. SATs are a heterogeneous group of skin tumors usually found as solitary, sporadic lesions with mostly benign behaviour; however, certain specific types of tumors may be an indication of some complex genetic syndromes like Cowden's syndrome and Muir Torre syndrome. ${ }^{[1,2]}$ These tumors are derived from multipotent undifferentiated cells present within the epidermis or its appendageal structures and the histologic features of the tumor are related to the activation of molecular pathways responsible for forming the mature adnexal structure. ${ }^{[1]}$ This study was undertaken to analyze the spectrum and histopathological profile of adnexal tumors of the skin.

\section{Material and Methods}

The present study was a cross-sectional, descriptive study conducted over a period of 5 years (October 2012 October2017) in the Department of Pathology, VIMSAR, Burla. Approval from institutional ethical committee was taken for the study. Patients with suspected skin adnexal tumors attending the out patients department of dermatology were recruited for the study. Demographic and clinical details of patients were documented. The excised specimens were fixed in $10 \%$ formalin, properly processed and stained using hematoxylin and eosin (H\&E) stain and subjected for microscopic evaluation. Immunohistochemistry (IHC) was performed as and when required. All the slides were reviewed, diagnosed and classified as SATs arising from sebaceous glands, hair follicles or sweat glands. Necessary statistical analysis was done using Microsoft Office Excel 2007. The concordance of clinical and histopathological diagnoses was accessed.

\section{Results}

A total of 60 patients ( 38 males and 22 females) with SATs were evaluated. The male to female ratio was $1.7: 1$. Out of 60 cases, $47(78.33 \%)$ were benign while only $13(21.66 \%)$ were malignant SATs. The sweat gland tumors accounted for $27(45 \%)$ cases, sebaceous gland tumors $19(31.66 \%)$ cases and hair follicle tumors $14(23.33 \%)$ cases according to direction of differentiation (Table 1). Among the benign SATs, eccrine poroma constituted 10(16.66\%) cases, sebaceous adenoma 9(15\%) cases, syringoma and pilomatricoma $7(11.66 \%)$ cases each, nodular hidradenoma and trichoepithelioma 3(5\%) cases each whereas, eccrine spiradenoma, sebaceoma, proliferating trichilemmal tumor and trichoblastoma constituted 2(3.33\%) cases each (Table 1). Among malignant SATs, sebaceous carcinoma constituted $8(13.33 \%)$ cases whereas malignant poroma 
\& malignant nodular hidradenoma 2(3.33\%) each and adenoid cystic carcinoma constituted only 1(1.66\%) case (Table 1). Clinical diagnosis was discordant with histopathological diagnosis in 8 cases. The age group wise distribution of SATs is depicted in (Table 2) and the site wise distribution is shown in (Table 3). The size of tumors (maximum dimension) was less than $1.5 \mathrm{~cm}$ in $42(70 \%)$ cases, between $1.6 \mathrm{~cm}$ to $2.5 \mathrm{~cm}$ in $9(15 \%)$ cases, between $2.6 \mathrm{~cm}$ to $4 \mathrm{~cm}$ in $7(11.66 \%)$ cases and more than $4 \mathrm{~cm}$ in $2(3.33 \%)$ cases.

Table 1: Proportions of various skin adnexal tumors according to direction of differentiation $(n=60)$.

\begin{tabular}{|c|c|c|c|c|}
\hline Category & $\begin{array}{l}\text { Direction Of } \\
\text { Differentiation }\end{array}$ & \multicolumn{2}{|c|}{ Types of skin adnexal tumors } & $\begin{array}{c}\text { Number Of Cases with } \\
\text { percentage }\end{array}$ \\
\hline \multirow{8}{*}{1} & \multirow{8}{*}{ Sweat Gland } & \multirow{4}{*}{ Benign } & Eccrine Poroma & $10(16.66 \%)$ \\
\hline & & & Syringoma & $7(11.66 \%)$ \\
\hline & & & Nodular Hidradenoma & $3(5 \%)$ \\
\hline & & & Eccrine Spiradenoma & $2(3.33 \%)$ \\
\hline & & \multirow{3}{*}{ Malignant } & Malignant Poroma & $2(3.33 \%)$ \\
\hline & & & Malignant Nodular Hidradenoma & $2(3.33 \%)$ \\
\hline & & & Adenoid Cystic Carcinoma & $1(1.66 \%)$ \\
\hline & & Total & & $27(45 \%)$ \\
\hline \multirow{4}{*}{ II } & \multirow{4}{*}{ Sebaceous Gland } & \multirow{2}{*}{ Benign } & Sebaceous Adenoma & $9(15 \%)$ \\
\hline & & & Sebaceoma & $2(3.33 \%)$ \\
\hline & & Malignant & Sebaceous Carcinoma & $8(13.33 \%)$ \\
\hline & & Total & & $19(31.66 \%)$ \\
\hline \multirow{5}{*}{ III } & \multirow{5}{*}{ Hair Follicle } & \multirow{4}{*}{ Benign } & Pilomatricoma & $7(11.66 \%)$ \\
\hline & & & Trichoepithelioma & $3(5 \%)$ \\
\hline & & & Proliferating Trichilemmal Tumor & $2(3.33 \%)$ \\
\hline & & & Trichoblastoma & $2(3.33 \%)$ \\
\hline & & Total & & $14(23.33 \%)$ \\
\hline & Total & & & 60 \\
\hline
\end{tabular}

Table 2: Age group wise distribution of skin adnexal tumors $(n=60)$.

\begin{tabular}{|c|c|c|}
\hline SI No. & Age Group (in years) & Number of Cases with percentage \\
\hline 1 & $11-20$ & $08(13.33 \%)$ \\
\hline 2 & $21-30$ & $06(10 \%)$ \\
\hline 3 & $31-40$ & $09(15 \%)$ \\
\hline 4 & $41-50$ & $08(13.33 \%)$ \\
\hline 5 & $51-60$ & $11(18.33 \%)$ \\
\hline 6 & $61-70$ & $03(5 \%)$ \\
\hline 7 & $71-80$ & $\mathbf{6 0}$ \\
\hline
\end{tabular}


Table 3: Site distribution of skin adnexal tumors $(n=60)$.

\begin{tabular}{|c|c|c|}
\hline SI No. & Site Of Tumor & Number of Cases with percentage \\
\hline 1 & Scalp & $17(28.33 \%)$ \\
\hline 2 & Face & $10(16.67 \%)$ \\
\hline 3 & Neck & $09(15 \%)$ \\
\hline 4 & Trunk & $12(20 \%)$ \\
\hline 5 & Upper Limb & $05(8.33 \%)$ \\
\hline 6 & Lower Limb & $07(11.66 \%)$ \\
\hline & Total & $\mathbf{6 0}$ \\
\hline
\end{tabular}

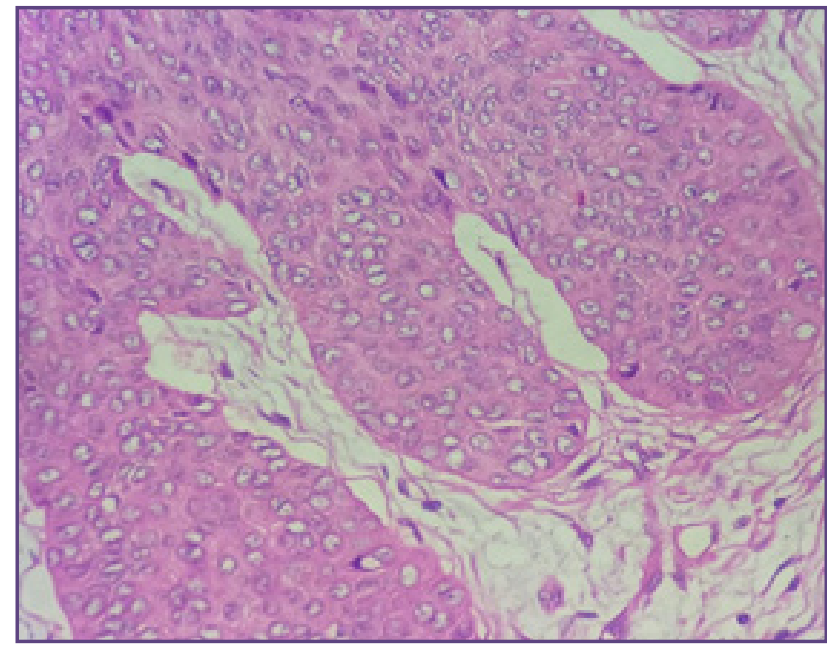

Fig. 1: Eccrine Poroma - Lobules of basaloid cells in lower portion of epidermis extending towards the dermis (H\&E, 100X).

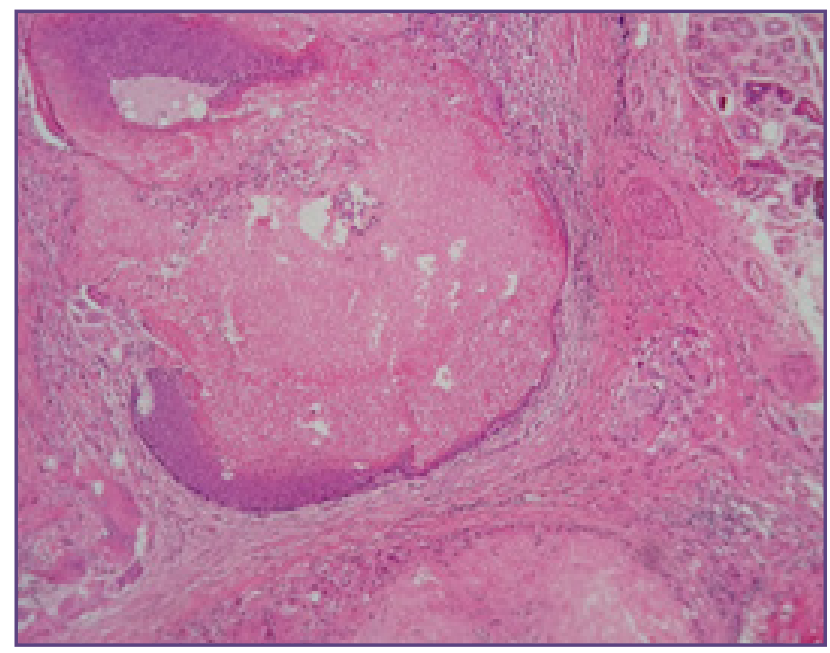

Fig. 3: Pilomatricoma - Islands of tumor cells having both basophilic cells and shadow cells (H\& E, 100X).

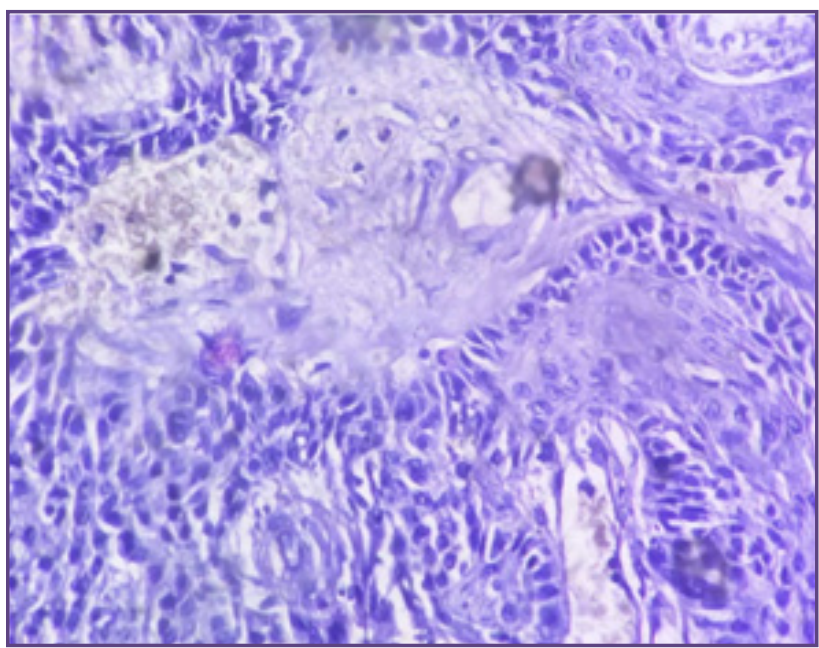

Fig. 2: Nodular Hidradenoma - Epithelial lobules comprising of clear cells and polygonal cells (H\&E, 400X).

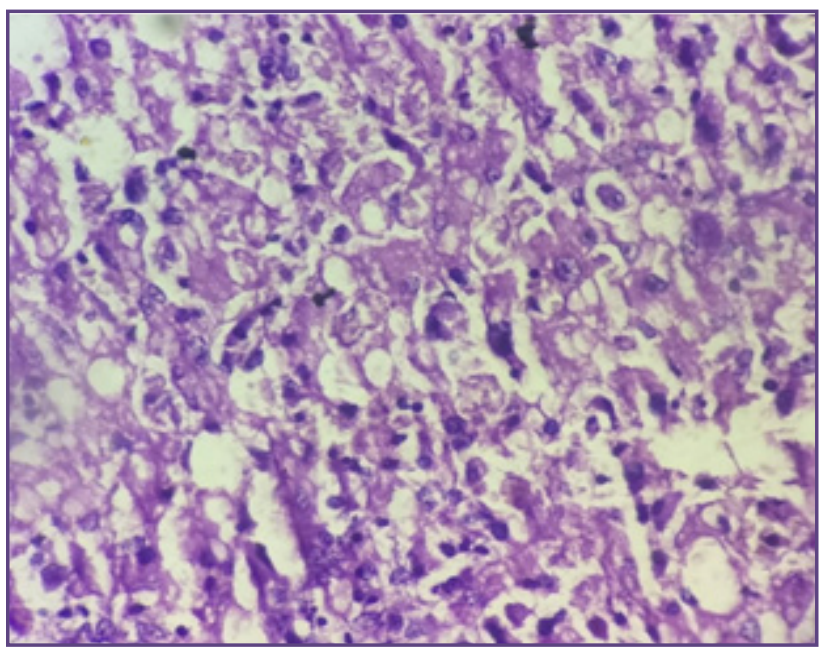

Fig. 4: Sebaceous Carcinoma - Cytologic atypia, mitotic activity and focal sebaceous cells with foamy cytoplasm (H\&E, 400X). 


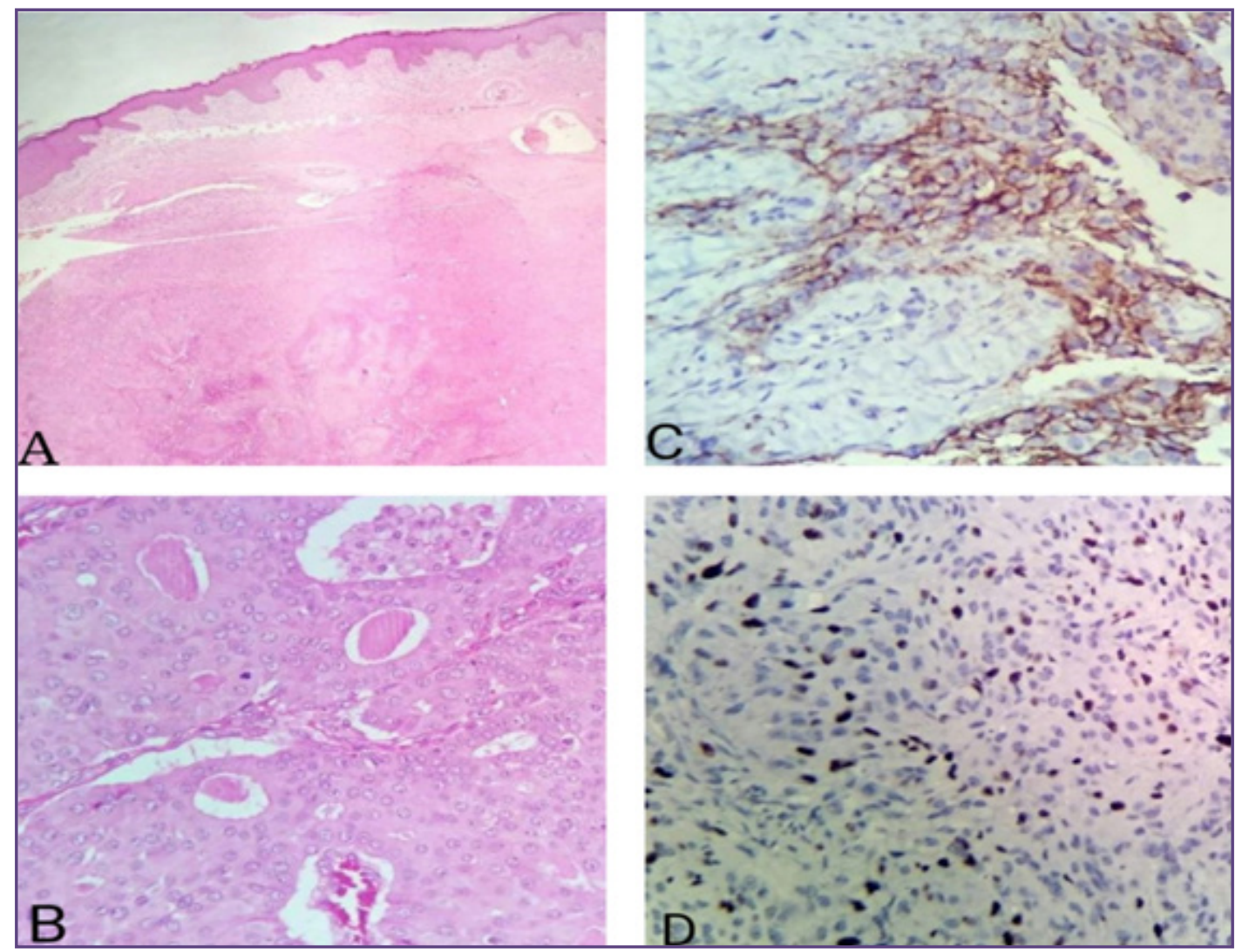

Fig. 5: Malignant Nodular Hidradenoma ( A)Tumor cells arranged in invasive nodular pattern with prominent cystic spaces (H\&E, 40X). (B) Atypical epithelial cells arranged in sheets (H\&E, 400X). (C)Immunohistochemistry showing EMA positivity(IHC,400X). (D)Immunohistochemistryshowing Ki $67>14 \%$ (IHC,400X).

\section{Discussion}

The large majority of SATs differentiate only along one adnexal line and this results in the formation of reasonably distinct types whose stucture, cytochemistry and immunohistochemistry can be correlated with those of the corresponding adnexa or even a subdivision thereof. ${ }^{[3]}$ The diagnosis of adnexal tumour poses great difficulties owing to a variety of reasons namely, the enormous types of tumors with their variants, the occurrence of multiple lines of differentiation in a single tumor as well as the complicated nomenclature. Adnexal tumors originate from multipotent undifferentiated stem cells which have the capability to differentiate along particular pathways, may be multiple. ${ }^{[1,2]}$ In the present study, the most frequent line of differentiation encountered was sweat gland differentiation(45\%), followed by sebaceous differentiation $(31.66 \%)$ and the least frequent being hair follicle differentiation $(23.33 \%)$. With regards to the line of differentiation of adnexal tumors, our findings are consistent with many other studies like Samaila et al..$^{[4]}$, Saha et al. ${ }^{[5]}$, Jindal et al. ${ }^{[6]}$, Gayathri et al. ${ }^{[7]}$, Radhika et al. ${ }^{[8]}$, Pentola et al. ${ }^{[9]}$ and Sharma et $a l .^{[10]}$ In this study, the proportion of adnexal tumors with sebaceous differentiation is comparatively more $(31.66 \%)$ than the above mentioned studies. ${ }^{[4,5,6,7,8,9,10]}$.

The male to female ratio of the patients was found to be 1.7:1 which was comparable to that of Pantola et al. ${ }^{[9]}(1.8: 1)$ . However, Saha et al. ${ }^{[5]}$ found female preponderance in their study (male to female ratio was 8:15).

In the Indian population, the overall incidence of SATs is very low as documented by several studies. ${ }^{[5,6,7,8,9]}$ The location of SATs varies with the histological types. By far, head and neck region is the most common location where adnexal tumors are frequently encountered, the other sites being axilla, trunk, legs etc. In the present study, the site of predilection was head and neck in 36(60\%) cases, followed by extremities (20\%) and trunk (20\%). The predominance of adnexal tumors in head and neck region is a well documented fact supported by most of the series in literature. ${ }^{[4,5,8,10]}$ This is due to the fact that this region is rich in pilosebaceous units, apocrine as well as eccrine glands, thereby providing a fertile environment for the development of adnexal tumors. 
Most of the tumors in our study $(70 \%)$ were $<1.5 \mathrm{~cm}$ in maximum dimension. Very rarely, the size of these tumors exceeded $4 \mathrm{~cm}$ in diameter. Jindal et al. ${ }^{[6]}$ also observed $76 \%$ of SATs to be $<2 \mathrm{~cm}$ in size. Eccrine poroma was the most commonly encountered benign SAT in our study with a total number of $10(16.66 \%)$ cases. Samaila et al. ${ }^{[4]}$ also found eccrine poroma $(32.7 \%)$ to be the most common benign SAT. However, Saha et al. ${ }^{[5]}$ and Nair $\mathrm{PS}^{[11]}$ found syringoma to be the most common SAT of head and neck region whereas Kaur et al. ${ }^{[12]}$, El Ochi et $a l .{ }^{[13]}$ and Rajalakshmi et al.$^{[14]}$ found pilomatricoma to be the most common benign SAT. Among the malignant SATs sebaceous carcinoma was the commonest neoplasm $8(13.33 \%)$ in our study. This finding was consistent with Sharma et al. ${ }^{[10]}$ and Kaur et a..$^{[12]}$ However, Samaila et $a l .{ }^{[4]}$ and Radhika et al ${ }^{[8]}$ found sweat gland carcinoma to be the most common malignant SAT.

Microscopically, eccrine poroma showed broad anastomosing bands of epithelial cells extending from epidermis to dermis having uniform cuboidal cells with round deeply basophilic nucleus (Figure 1). Syringoma showed numerous small ducts lined by two rows of epithelial cells and embedded in fibrous stroma. Some of these ducts have small, comma-like tails of epithelial cells, giving tadpole appearance. Nodular hidradenoma showed capsulated, well circumscribed epithelial lobules in the dermis, having two populations of cells; polyhedral cells with rounded nucleus \& slightly basophilic cytoplasm and round cells with small dark nucleus \& clear cytoplasm (Figure2).Eccrine spiradenoma showed lobules of epithelial cells in dermis consisting of peripheral small dark nuclei and central larger pale nuclei. Microscopically, pilomatricoma showed islands of basophilic and shadow cells in the lower dermis. The basophilic cells are arranged in the periphery or on one side of tumor islands; the shadow cells have distinct border and a central unstained area as a shadow of lost nucleus (Figure 3).Trichoepithelioma showed horn cysts and tumor islands consisting of basophilic cells arranged in lace like or adenoid pattern or solid aggregates. The tumor islands also exhibit peripheral palisading of their cells but lack retraction artifact typical of basal cell carcinoma. Trichoblastoma showed large islands of basaloid cells showing peripheral palisading in the dermis dispersed in a delicate fibrotic stroma without any connection with the epidermis. Due to presence of symmetry, circumscription with smooth margin, follicular pattern of lesional cells, lack of retraction artifact, lack of stromal edema \& lymphocytes it was precluded from the diagnosis basal cell carcinoma .Proliferating trichilemmal tumor presented as large elevated lobular mass with ulceration on scalp resembling squamous cell carcinoma. Microscopically, it showed multiple variably sized lobules of squamous epithelium showing abrupt keratinisation. These tumors differ from squamous cell carcinoma by a rather sharp demarcation from surrounding stroma as well as an abrupt mode of keratinisation and absence of extensive area of severe atypia. Sebaceous carcinoma, in our study were exclusively from meibomian gland origin. It occurs most frequently on the eyelids as observed in our study. The tumor is composed of irregular lobular formations of sebaceous cells as well as undifferentiated cells with moderate to marked nuclear pleomorphism (Figure 4).We came across a single rare case of adenoid cystic carcinoma showing cribriform pattern of growth and fibrous stroma histologically. The neoplastic basaloid cells are arranged in variably sized, smooth contoured islands comprising small uniform basaloid cells punctured by round rigid spaces, giving rise to Swiss cheese appearance. The lack of epidermal connection and absence of peripheral palisading of neoplastic cells and the presence of PAS positive material and perineural space invasion favour the diagnosis of adenoid cystic carcinoma over adenoid BCC. ${ }^{[15]}$ Malignant eccrine poroma showed polygonal cells arranged in cords, lobules and cribriform pattern having large hyperchromatic irregular shaped nuclei extending to dermis along with presence of mitosis and necrosis. The rarity of these lesion cannot be overemphasized; one large laboratory identified only 5 such lesions in a group of 750,000 cases over an 8 year period. ${ }^{[16]}$

Malignant nodular hidradenoma presented as a large scalp swelling with clinical diagnosis of Cock's peculiar tumor. Microscopy it showed a grenz zone between epidermis and dermis, tumor cells arranged in nodular pattern, prominent cystic spaces, high cellularity, marked cytologic atypia, clear cytoplasm, nuclear anaplasia, mitosis4/10HPF, necrosis (Figure 5A \& 5B). IHC showed epithelial membrane antigen (EMA) reactivity in tubular structures and $\mathrm{Ki} 67>14 \%$ suggesting high proliferative index (Figure 5C \& 5D). IHC has little, if any role in differentiating between the various types of adnexal tumors. Carcinoembryonic antigen positivity indicates a ductal differentiation, cytokeratin indicates follicular differentiation while sebaceous differentiation is suggested by EMA positivity. IHC may play an important role in distinguishing primary adnexal cutaneous carcinoma from metastatic carcinoma. p63 and CK5/6 positivity favour a primary cutaneous adnexal carcinoma over a metastatic carcinoma. ${ }^{[1,2]}$

\section{Conclusion}

SATs are rare neoplasm with benign tumor being far more common. Majority of tumors can be classified into different subgroups on the basis of light microscopy alone. The commonest variant are those of sweat gland origin; 
which is also reflected in our study. Most tumors are asymptomatic and often difficult to diagnose clinically. So the clinician mostly rely upon the histopathology for diagnosis of SATs.

\section{References}

1. Klein W, Chan E, Seykora JT. Tumors of the epidermal appendages. In: Elder DE, Elenitsas R, Johnson BL Jr, Murphy GF, editors. Lever's Histopathology of the Skin. 9th ed. Philadelphia: Lippincott Williams and Wilkins; 2005. pp. 867-926.

2. Santa Cruz DJ. Tumors of the skin. In: Fletcher CD, editor. Diagnostic Histopathology of Tumors. 3rd ed. Vol. 2. Philadelphia: Churchill Living Stone Elsevier; 2007. pp. 1423-526.

3. Rosai J., "Tumors and tumor like conditions" In: Rosai And Ackerman^S Surgical Pathology,10th edition.Vol.1. St. Louis, USA: Elsevier Mosby; 2011.p.137

4. Samaila MO. Adnexal skin tumors in Zaria, Nigeria. Ann Afr Med. 2008;7:6-10.

5. Saha A, Das NK, Gharami RC, Chowdhury SN, Datta PK. A clinico-histopathological study of appendageal skin tumors affecting head and neck region in patients attending the dermatology opd of a tertiary care centre in Eastern India. Indian J Dermatol. 2011;56:33-6.

6. Jindal U, Patel R. Study of adnexal tumors of the skin: A three year study of 25 cases. Int J Pathol.2012;13:3.

7. Gayathri SS, Alavandar E, Kumar SA. An analysis of skin appendageal tumors in South India. J Evol Med Dent Sci. 2012;1:907-10.
8. Radhika K, Phaneendra BV, Rukmangadha N, Reddy MK.. A study of biopsy confirmed skin adnexal tumours: Experience at a tertiary care teaching hospital. J Clin Sci Res. 2013;2:132-8.

9. Pantola C, Kala S, Agarwal A, Amit S, Pantola S. Cutaneous adnexal tumours: A clinicopathological descriptive study of 70 cases. World J Pathol. 2013;2:77-82.

10. Sharma A, Paricharak DG, Nigam JS, Rewri S, Soni PB, Omhare A, et al. Histopathological study of skin adnexal tumours-Institutional study in South India. J Skin Cancer. 2014;4:543756.

11. Nair PS. Aclincopathologic study of skin appendageal tumors. Indian J Dermatol Venereol Leprol 2008;74:550.

12. Kaur K, Gupta K, Hemrajani D, Yadav A, Mangal K. Histopathologic analysis of skin adnexal tumors: A three year study of 110 cases at a tertiary care center. Indian J Dermatol 2017;62:400-6

13. El Ochi MR, Boudhas A, Allaoui M, Rharrassi I, Chahadi H, Al Bouzidi A, et al. Skin adnexal tumors : Histological study about 96 cases. Pan Afr Med J 2015;20:389

14. Rajalakshmi V, Selvakumar S, Rajeswari K, Meenakshisundaram K, Veena G, Ramachandran P. Case series of skin adnexal tumors.

15. Kamiya H, Oyama Z, Kitajima Y. "Apocrine" poroma: review of the literature and case report. J Cutan Pathol 2001;28:101-4.

16. Abenoza P, Ackerman A B, Di Leonardo M. Porocarcinoma. In: Neoplasms with Eccrine Differentiation. Lea\&Febiger, Philadelphia;1990.p 415-431.

*Corresponding author:

Dr. Dilip Kumar Sa, Gourishankar Mandir Road, Near Itwari Bazar, Raigarh, Chhattisgarh, India, PIN 496001.

Phone: +91 7024449837

Email: dr.dilip.kmc@gmail.com

Financial or other Competing Interests: None. 